Vol 14, Issue 10, 2021

\title{
REDUCTIONS IN MEDICATION WASTAGE AND COSTS IN A PEDIATRIC INTENSIVE CARE UNIT BY CHANGING THE ORDER ENTRY SYSTEM
}

\author{
IMAN KHORSHIDI-MALAHMADI, SETAREH SIMA, ZAHRA ALLAMEH*
}

Department of Clinical Pharmacy, School of Pharmacy and Pharmaceutical Science, Isfahan University of Medical Sciences, Isfahan, Iran. Email: Zahraallameh@gmail.com

Received: 23 June 2021, Revised and Accepted: 10 September 2021

\section{ABSTRACT}

Objective: The intensive care unit (ICU) drug therapies have a significant impact on hospital costs, and reducing these costs has become a critical concern for hospitals. In this study, the researchers tested the theory on whether changing the ordering system of medications in the pediatric ICU $(\mathrm{PICU})^{1}$, reduces drug wastage so that the nurse can request a fraction of one vial or ampule. More precisely, the study aimed to reduce the medication cost and wastage in our pediatric center.

Methods: This study was conducted in the 16-bed PICU of Imam Hossein Hospital, which is a referral tertiary care teaching pediatric hospital with 185 beds in ten wards. A fractional ordering alternative was added to the hospital information system of the PICU of the pediatric hospital. Nurses were taught by the hospital pharmacist to understand the new way of ordering the drugs. Several highly used drugs were chosen for the intervention. The data were analyzed by an independent sample t-test using SPSS software.

Results: Based on the results, changing the method of requesting medications for PICU patients and the random checking of floor stocks and the expired drugs in PICU reduced the number and cost of all medications.

Conclusion: Overall, the collaboration of nurses and pharmacists can lead to cost savings in hospitals.

Keywords: Hospital, Medication, Pharmacists.

(C) 2021 The Authors. Published by Innovare Academic Sciences Pvt Ltd. This is an open access article under the CC BY license (http://creativecommons.org/ licenses/by/4.0/) DOI: http://dx.doi.org/10.22159/ajpcr.2021v14i10.42577. Journal homepage: https://innovareacademics.in/journals/index.php/ajpcr

\section{INTRODUCTION}

The intensive care unit (ICU) drug therapies have a significant impact on hospital costs [1], and reducing these costs has changed into a vital concern for hospitals. Accordingly, multidisciplinary collaboration programs are necessary for optimizing ICU pharmacotherapy. Clinical and hospital pharmacists in hospitals are also considered as implementing methods for reducing the cost of drug therapy while maintaining safety and efficacy.

In the pediatric ICU (PICU) of Imam Hossein Children's Hospital, the nurses were requesting the full amount of a vial because the hospital information system (HIS) did not allow the request of less than one vial. Nonetheless, a half or a quarter of one vial was practically used for one patient. Although the remaining amount of medicine in the vial would have been applied if required for another patient, it was not a predicted and systematic service. The previous evidence indicated that there are non-standard vials and more than the allowable amount of unused ones in the PICU stock. Unfortunately, the majority of such vials were never used and discarded by the nurses. This dumping of drugs imposes various costs on the hospital, leading to an increase in hospital costs.

In this study, the researchers tested the theory on whether changing the ordering system of medications in the PICU, reduces the drug cost and wastage in a way that the nurse can request a fraction of one vial or ampule.

\section{METHODS}

Imam Hossein Hospital, Isfahan, Iran is a referral tertiary care teaching pediatric health center with 185 beds in ten wards, and this study was conducted in the 16-bed PICU of the above-mentioned hospital.

1. Pediatric Intensive Care Unit
The PICU was selected for the intervention considering its importance in this pediatric center with ten other wards, and the applied medications by this unit include $25 \%$ of hospital costs on average.

\section{Intervention}

A fractional ordering option was added to the HIS (Pooya Samaneh Diva Company, Sari, Iran). In addition, several highly used drugs were chosen for the intervention. It should be noted that these drugs had the most surplus and wastage due to the primary assessments of the pharmacist in random checks in the PICU. Therefore, it was considered for the selection of these drugs. The drugs were pantoprazole $40 \mathrm{mg}$

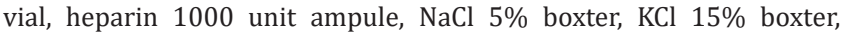
ampicillin $500 \mathrm{mg}$ vial, aminoacid 10\% infant boxter, intralipid $20 \%$ boxter, phenobarbital $200 \mathrm{mg}$ ampule, acetaminophen $1 \mathrm{~g}$ ampule and vancomycin $500 \mathrm{mg}$ vial.

A part-time pharmacist was assigned to the ICU for 4 months to educate the nurses, who were taught by the hospital pharmacist to understand the new way of ordering the drugs. Further, nurses found that some multiple-dose drugs or drugs with large doses should be shared between patients and they cannot discard them in this new approach. This new ordering system was named the fractional system of ordering medications. In this new system, the nurse could order a fraction of the drug rather than a full vial or ampule. It is noteworthy that educating the nurses was a continuous process while not being limited to one or two session(s), and the hospital pharmacist daily followed the track of the ordering pattern of nurses.

The drug usage data during 2019-2020 were extracted by the HIS and then compared with those of 2018-2019 when there was no fractional system implementation. Moreover, the hospital pharmacist 
gathered the data of the expired drugs during 1 year before and after the intervention.

The following formula was used for calculating the percentage of reductions in the number and cost of each drug before and after the intervention:

The cost or number of drugs per patient admitted before the intervention - the cost or number of drugs per patient admitted after the intervention/The cost or number of drugs per patient admitted before the intervention * 100

The data were analyzed with SPSS software. The percentage of reductions in the cost and number of drugs per bed, as well as the $\mathrm{p}$-value for comparing the number and cost of PICU drugs per bed, before and after the intervention, was calculated by an independent sample t-test.

\section{RESULTS}

In general, 1050 and 1080 patients were admitted in 2019-2020 and 2018-2019, respectively. As shown in Table 1, the entire number and cost of the selected drugs per admitted patient reduced after the intervention.

Although the number and cost of the applied medications in the PICU of Imam Hossein Hospital reduced with the intervention, this reduction was not statistically significant. An independent sample t-test was performed on the data of all drugs. The p-values for changes in the number of drugs per patient admitted and the cost were 0.86 and 0.87 , respectively.

Fig. 1 shows changes in the number of applied medications in a year per admitted patient before and after the intervention. The number of all applied drugs per patient has reduced after the intervention except for heparin.

The changes in the cost of the used medications in a year per admitted patient before and after the intervention are depicted in Fig. 2 (Prices are calculated in rials).

The percentage of medication number and cost reduction due to the intervention is summarized in Table 2.

In addition to these results, the cost of the expired drugs was lowered by 13562360 rials in 1 year. It was further found that the expired drugs were completely eliminated due to a rotation of drug stocks and the regular monitoring of expiration dates. Thus, reducing floor stocks by this system and random checking by the hospital pharmacist can effectively reduce expired drugs.

\section{DISCUSSION}

Based on the findings of our study, changing the way of requesting medications for PICU patients and the random checking of floor stocks and expired drugs in PICU reduced the number and cost of all medications. Moreover, minimizing prescription costs while maintaining quality is a core element of delivering high-value healthcare.

There are various strategies to achieve savings although, no research, to the best of our knowledge, has so far focused on determining the most effective approach in this regard. Therefore, finding a way to reduce costs in PICU will lead to cost savings and reduce the problems associated with drug storage. Several methods exist for decreasing the costs and wastage of medications in hospitals. For example, one of the most effective ways is to warn when prescribing expensive drugs in computerized provider order entry systems, which could reduce drug costs in some studies [2,3].

In one study aiming at reducing hospital costs, a computer-assisted drug medication alert system was used to alert physicians to several expensive drugs when requesting medication and announce prices, reducing hospital costs [4]. Although using a computer system reduces common drug errors, new errors are simultaneously created using this method. Duplicate orders, unit errors, the use of free text, parameterization flaws, and poor usability of software are probably the root of many prescribing errors [5,6]. The results of a similar study revealed that changing the computerized ordering system could significantly reduce costs [7]

Another study found that changes in the cancer drug ordering system decreased both error and drug wastage rates. Overall, the safety of their parenteral chemotherapy ordering processes within their electronic health records improved after the implementation of automated dose-banding. By standardizing the administered doses for three chemotherapy agents, they were also able to increase total drug savings and associated drug cost savings [8].

Table 1: The cost and number of all medications per patient before and after the intervention and the reduction percentage

\begin{tabular}{|c|c|c|c|}
\hline $\begin{array}{l}\text { Medication } \\
\text { usage/cost }\end{array}$ & $\begin{array}{l}\text { Before } \\
\text { intervention }\end{array}$ & $\begin{array}{l}\text { After } \\
\text { intervention }\end{array}$ & $\begin{array}{l}\text { Percentage of } \\
\text { reduction }\end{array}$ \\
\hline $\begin{array}{l}\text { Number } \\
\text { of used } \\
\text { medications } \\
\text { per patient }\end{array}$ & 19.70 & 17.62 & 10.55 \\
\hline $\begin{array}{l}\text { Cost of used } \\
\text { medications } \\
\text { per } \\
\text { patient (Rials) }\end{array}$ & 1488040 & 1330567 & 10.58 \\
\hline
\end{tabular}

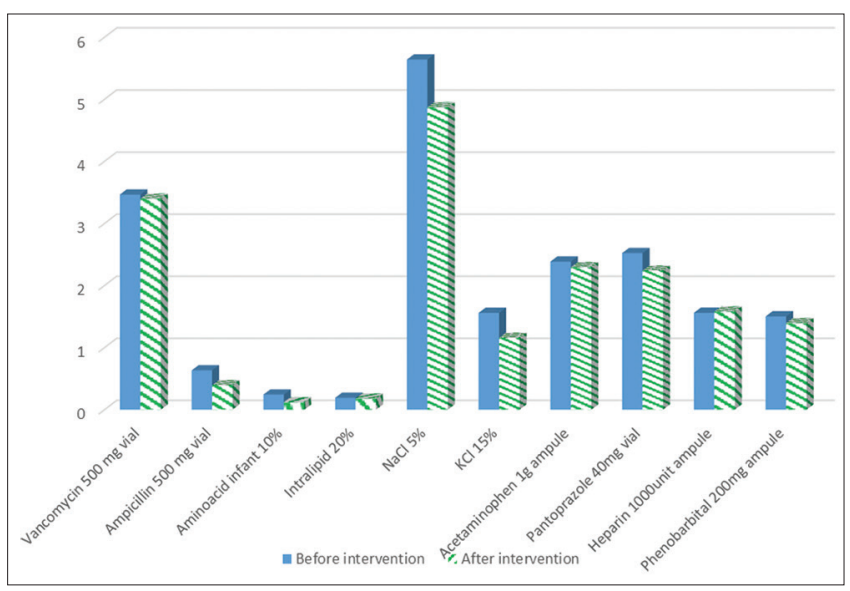

Fig. 1: Changes in the number of the applied medications in a year per admitted patient before and after the intervention

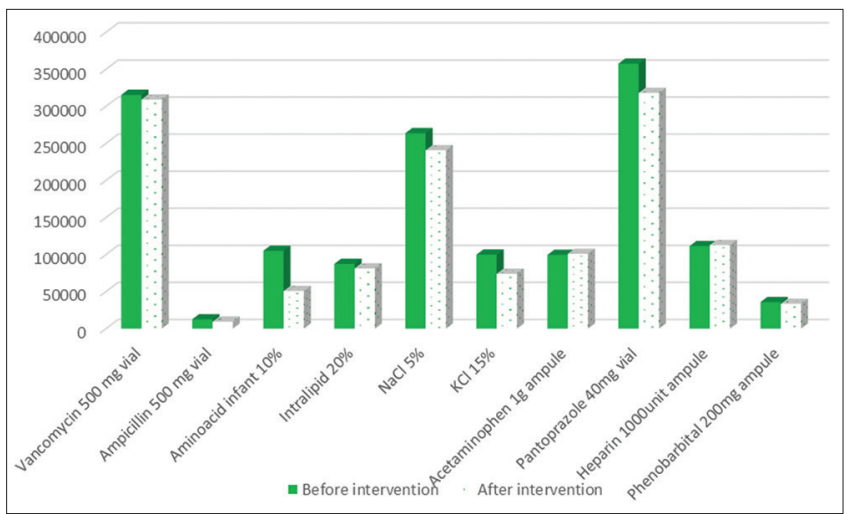

Fig. 2: Changes in the cost of the applied medications in a year per admitted patient before an after the intervention. Prices are computed in rials 
Table 2: Percentage of medication number and cost reduction with the intervention

\begin{tabular}{lll}
\hline $\begin{array}{l}\text { Medication } \\
\text { name }\end{array}$ & $\begin{array}{l}\text { Percentage of } \\
\text { reductions in the } \\
\text { number per patient } \\
\text { with intervention }\end{array}$ & $\begin{array}{l}\text { Percentage of } \\
\text { reductions in costs } \\
\text { per patient with } \\
\text { intervention }\end{array}$ \\
\hline $\begin{array}{l}\text { Vancomycin } \\
\text { 500 mg vial }\end{array}$ & 1.98 & 1.97 \\
$\begin{array}{l}\text { Ampicillin } \\
500 \text { mg vial }\end{array}$ & 38.11 & 25.40 \\
$\begin{array}{l}\text { Aminoacid infant } \\
10 \%\end{array}$ & 51.02 & 51.60 \\
$\begin{array}{l}\text { Intralipid 20\% } \\
\text { NaCl 5\% }\end{array}$ & 7.41 & 6.90 \\
KCl 15\% & 13.65 & 8.73 \\
$\begin{array}{l}\text { Acetaminophen } \\
\text { g ampule }\end{array}$ & 25.84 & 25.84 \\
Pantoprazole & 11.18 & -1.41 \\
40 mg vial & & 11.04 \\
$\begin{array}{l}\text { Heparin } \\
1000 \text { unit ampule }\end{array}$ & -1.22 & -1.21 \\
$\begin{array}{l}\text { Phenobarbital } \\
\text { 200 mg ampule }\end{array}$ & 7.22 & 6.45 \\
\hline
\end{tabular}

NaCl: Sodium chloride; KCl: Potassium chloride

The problem of wasting and not using drugs in children's hospitals is not unique to our hospital and has been reported in other studies as well. For example, one study measured the number of surplus drugs in the pediatric ward. The study aimed to determine the amount of unused intravenous and intramuscular drugs and the financial burden that these drugs impose on the system. The total wastage cost/total drug cost ratio was 0.495 , meaning that about half of the drugs are wasted, it was concluded that appropriate formulations for the pediatric population should be developed if commercial intramuscular and intravenous drugs are used by the pediatric population. The production of multipledose formulations by pharmaceutical companies will also be helpful in this regard. Finally, reducing drug wastage will automatically decrease drug costs [9].

One similar study assessed the reasons for antibiotic wastage in a pediatric hospital and reported patient discharge, medication order discontinuation or change, and misplaced doses as the main reasons for antibiotic wastage. In addition, meropenem, micafungin, and amphotericin B liposomal were among the antibiotics with the highest wasted costs. To reduce this drug waste and hospital costs, they proposed four process improvement measures [10]. Based on the results of a study regarding pediatric anesthesia care for determining the cost of the used drugs without documentation, the uncontrolled availability of drugs in floor stocks and their undocumented use were important causes of increasing drug costs and wastage [11]. In a 17-month study in Texas Children Hospital, medication errors reduced after the implementation of the workflow management system and led to significant decreases in cost and wastage [12].

According to Weinger [13], the incomplete use of vials and syringes of anesthetic drugs was the reason for an increase in the cost of routine anesthesia care. In another study, the technique of drug pooling and unit dose dispensing for antibiotics was used to reduce the waste of antibiotics in a hospital, and this technique was able to reduce drug costs [14]. To reduce the cost of medication and the waste of anticancer drugs, in one study, the calculated dose was rounded upward to the full next vial if the calculated dose exceeded above $50 \%$ of the next appropriate vial strength while it was rounded downward to the full previous vial if the calculated dose did not exceed above $50 \%$ of the next appropriate vial strength. This reduced drug costs without reducing effectiveness [15].

According to Hess, pharmacists and physicians have an important role in reducing drug wastage and costs by optimizing vial combination and sharing among patients [16]. The results of a study in a hospital in Kualampur showed that the deterioration of a patient's clinical conditions is the most important cause of returned parental chemotherapy regimens and wastage [17]

Based on the findings of a 6-week study in the operation room of a hospital, drug wastage and cost could be controlled by the behavioral changes of physicians, the preparation of standard doses from singledose preparations, and cost training programs [18]. As shown by previous research, the pharmacist has a critical role in drug-related problem monitoring and cost savings in hospitals [19].

Many studies have shown the effectiveness of the presence of a pharmacist or a clinical pharmacist in hospitals using a computer system to request medication for reducing medication errors and hospital costs [20-25]. The findings of one study demonstrated the effectiveness of the presence of a clinical pharmacist in reducing medication errors when using a computer system [26]. The results of a systematic review and meta-analysis on the cost-effectiveness of entering a pharmacist in the clinical wards of the hospital represented that it is effective in improving drug treatment and it is a cost-effective process [27]. In another study, the consultation of pharmacists with physicians reduced the number and cost of antipsychotic medications [28]. Pharmacist's interventions in the ICU of a Malaysian hospital resulted in significant cost savings in terms of drug expenses [29].

As mentioned in another study, the pharmacist can significantly contribute to cost savings and a clinical pharmacist is an important and cost-effective member of the PICU team [30].

\section{CONCLUSIONS}

In this single-center before-after study, the new ordering system (fractional ordering) reduced costs in the PICU. The implementation of new ordering systems and the collaboration of pharmacists with nurses can reduce drug costs in hospitals. The application of this approach for managing medications in the ICU may improve efficiency, outcomes, and the cost of care for critically ill patients.

\section{ACKNOWLEDGMENTS}

We would like to thank the nurses who took part in the project. In addition, we are thankful to the IT manager of the hospital, Mrs. Zahra Abtahi who helped us in performing the new Order Entry System.

\section{AUTHORS' CONTRIBUTIONS}

Dr. Zahra Allameh was involved in planning the study and writing the manuscript. Dr. Iman Khorshidi-malahmadi collected and analyzed the data and reviewed the manuscript. Dr. Setareh Sima assisted in collecting data and editing the manuscript.

\section{CONFLICTS OF INTEREST}

The authors affirm no conflicts of interest, finance, or otherwise.

\section{FUNDING}

The author(s) received no financial support for the research, authorship, and/or publication of this article.

\section{REFERENCES}

1. Weber RJ, Kane SL, Oriolo VA, Saul M, Skledar SJ, Dasta JF. Impact of intensive care unit (ICU) drug use on hospital costs: A descriptive analysis, with recommendations for optimizing ICU pharmacotherapy. Crit Care Med 2003;31:S17-24.

2. Gipson G, Kelly JL, McKinney CM, White AA. Optimizing prescribing practices of high-cost medications with computerized alerts in the inpatient setting. Am J Med Qual 2017;32:278-84.

3. Curtain C, Peterson GM, Tenni P, Bindoff IK, Williams M. Outcomes of a decision support prompt in community pharmacy-dispensing software to promote step-down of proton pump inhibitor therapy. $\mathrm{Br} \mathrm{J}$ 
Clin Pharmacol 2011;71:780-4

4. Conway S, Brotman D, Pinto B, Merola D, Feldman L, Miller R, et al. Impact of displaying inpatient pharmaceutical costs at the time of order entry: Lessons from a tertiary care center. J Hosp Med 2017;12:639-45.

5. Vélez-Díaz-Pallarés M, Díaz AM, Caro TG, Oliveros NV, DelgadoSilveira E, García MM, et al. Technology-induced errors associated with computerized provider order entry software for older patients. Int J Clin Pharm 2017;39:729-42.

6. Charpiat B, Bedouch P, Conort O, Rose FX, Juste M, Roubille R, et al. Opportunities for medication errors and pharmacist's interventions in the context of computerized prescription order entry: A review of data published by French hospital pharmacists. Ann Pharm Fr 2012;70:62- 74

7. Jaeger C, Sullivan P, Waymack J, Griffen DG. Effectively reducing amylase testing using computer order entry in the emergency department: Quality improvement without eliminating physician choice. J Innov Health Inform 2017;24:907.

8. Fahey OG, Koth SM, Bergsbaken JJ, Jones HA, Trapskin PJ. Automated parenteral chemotherapy dose-banding to improve patient safety and decrease drug costs. J Oncol Pharm Pract 2020;26:345-50.

9. Bucak IH, Almis H, Dogan CN, Turgut M. The status of drug wastage in the pediatric emergency department of a tertiary hospital. Avicenna J Med 2020;10:10-4.

10. MacBrayne CE, Williams MC, Obermeier H, Child J, Heizer JW, Millard M, et al. Anti-infective waste in a pediatric institution: Pinpointing problems in the process. Hosp Pharm 2020;55:220-3.

11. Nava-Ocampo AA, Alarcón-Almanza JM, Moyao-García D, Ramírez- Mora JC, Salmerón J. Undocumented drug utilization and drug waste increase costs of pediatric anesthesia care. Fundam Clin Pharmacol 2004;18:107-12.

12. Davis SJ, Hurtado J, Nguyen R, Huynh T, Lindon I, Hudnall C, et al. Innovations in medication preparation safety and wastage reduction: Use of a workflow management system in a pediatric hospital. Hosp Pharm 2017;52:54-9.

13. Weinger MB. Drug wastage contributes significantly to the cost of routine anesthesia care. J Clin Anesth 2001;13:491-7.

14. Ughasoro MD, Nwakoby IC, Onwujekwe OE, Odike AI. Drug pooling: A cost-saving strategy to enhance antibiotics availability for pediatric in-patient in Nigeria. Niger J Clin Pract 2019;22:232-7.

15. Dooley MJ, Singh S, Michael M. Implications of dose rounding of chemotherapy to the nearest vial size. Support Care Cancer 2004;12:653-6.

16. Hess LM, Cui ZL, Li XI, Oton AB, Shortenhaus S, Watson IA. Drug wastage and costs to the healthcare system in the care of patients with non-small cell lung cancer in the United States. J Med Econ 2018;21:755-61.

17. Ang ZY, Cheah KY, Abdullah NB, Samsuri SB, Lee SH, Yem AW, et al. Parenteral cytotoxic drug wastage at a tertiary hospital in Kuala Lumpur: How much and why? J Oncol Pharm Pract 2020;26:1306-17.

18. Peker K. The wastage and economic effects of anaesthetic drugs and consumables in the operating room. Turk J Anaesthesiol Reanim 2020;48:321-7.

19. Lucca JM, Ramesh M, Narahari GM, Minaz N. Impact of clinical pharmacist interventions on the cost of drug therapy in intensive care units of a tertiary care teaching hospital. J Pharmacol Pharmacother 2012;3:242-7

20. Raimbault-Chupin M, Spiesser-Robelet L, Guir V, Annweiler C, Beauchet $\mathrm{O}$, Clerc MA, et al. Drug related problems and pharmacist interventions in a geriatric unit employing electronic prescribing. Int $\mathrm{J}$ Clin Pharm 2013;35:847-53.

21. Zaal RJ, Jansen MM, Duisenberg-van Essenberg M, Tijssen CC, Roukema JA, van den Bemt PM. Identification of drug-related problems by a clinical pharmacist in addition to computerized alerts. Int J Clin Pharm 2013;35:753-62.

22. Ronan S, Shannon N, Cooke K, McKeon T, Walsh EK, Kearney A, et al. The role of the clinical pharmacist in an Irish University teaching hospital: A mixed-methods study. Pharmacy 2020;8:14

23. Chen PZ, Wu CC. Clinical and economic impact of clinical pharmacist intervention in a hematology unit. J Oncol Pharm Pract 2020;26:866- 72.

24. Leache L, Aquerreta I, Aldaz A, Idoate A, Ortega A. Evidence of clinical and economic impact of pharmacist interventions related to antimicrobials in the hospital setting. Eur J Clin Microbiol Infect Dis 2018;37:799-822.

25. Randolph LA, Walker CK, Nguyen AT, Zachariah SR. Impact of pharmacist interventions on cost avoidance in an ambulatory cancer center. J Oncol Pharm Pract 2018;24:3-8.

26. Wang JK, Herzog NS, Kaushal R, Park C, Mochizuki C, Weingarten SR. Prevention of pediatric medication errors by hospital pharmacists and the potential benefit of computerized physician order entry. Pediatrics 2007;119:e77-85.

27. Dawoud DM, Smyth M, Ashe J, Strong T, Wonderling D, Hill J, et al. Effectiveness and cost effectiveness of pharmacist input at the ward level: A systematic review and meta-analysis. Res Social Adm Pharm 2019; $15: 1212-22$

28. Hashimoto Y, Tensho M. Effect of pharmacist intervention on physician prescribing in patients with chronic schizophrenia: A descriptive pre/ post study. BMC Health Serv Res 2016;16:150.

29. Zaidi ST, Hassan Y, Postma MJ, Ng SH. Impact of pharmacist recommendations on the cost of drug therapy in ICU patients at a Malaysian hospital. Pharm World Sci 2003;25:299-302.

30. Krupicka MI, Bratton SL, Sonnenthal K, Goldstein B. Impact of a pediatric clinical pharmacist in the pediatric intensive care unit. Crit Care Med 2002;30:919-21 